\title{
Perancangan dan Pembuatan Aplikasi Pepak Basa Jawa Menggunakan MobiOne Studio
}

\author{
Anglila Nayanggita ${ }^{1)}$, Kodrat Iman Satoto ${ }^{2)}$, Rinta Kridalukmana ${ }^{2)}$ \\ Program Studi Sistem Komputer, Fakultas Teknik, Universitas Diponegoro \\ Jalan Prof. Sudharto, Tembalang, Semarang, Indonesia \\ anglilanay507@gmail.com
}

\begin{abstract}
Indonesia is a nation that has a diversity of cultures and the arts, one of which is Javanese language. Javanese language is a heritage that should be preserved because it is still taught in schools and used in everyday life. The main book to learn Javanese language is Pepak Basa Jawa; a book that contains the essence of Javanese language. The rapid increase of technological development provides easiness for people, especially the pressence of gadgets. Therefore, the making of Pepak Basa Jawa in an application it needed to be a learning media to learn and conserve Javanese language for Indonesian people. The application is practically and attractively packed through iOS based mobile devices.

Application Pepak Basa Jawa is built using MobiOne Studio software. Multimedia development method used is the Multimedia Development Life Cycle (MDLC) which consists of six stages: concept, design, collection of material, manufacture, testing, and distribution. The Black Box test is used for application testing method.

The results of this study is in the form of an application named Pepak Basa Jawa that can run well on mobile devices based on $\mathrm{IOS}$. This application can be an alternative for the people of Indonesia as a medium of learning in learning the Javanese language.
\end{abstract}

Keywords: Application, Pepak Basa Jawa, iOS, MobiOne Studio

\section{PENDAHULUAN}

\subsection{Latar Belakang}

Indonesia merupakan salah satu bangsa yang memiliki banyak keanekaragaman. Keanekaragaman ini merupakan pemersatu serta warisan bagi bangsa Indonesia yang perlu dilestarikan. Keanekaragaman bangsa Indonesia yang perlu dilestarikan meliputi keanekaragaman suku, budaya, kesenian maupun bahasa daerah. Bahasa daerah khususnya Bahasa Jawa merupakan bahasa yang masih digunakan oleh masyarakat di pulau Jawa terutama di wilayah Jawa Tengah, Daerah Istimewa Yogyakarta (DIY), dan Jawa Timur sebagai alat komunikasi dalam kehidupan bermasyarakat. Bahasa Jawa juga merupakan salah satu pelajaran yang masih diajarkan di sekolah dari jenjang Sekolah Dasar (SD), Sekolah Menengah Pertama (SMP) hingga Sekolah Menengah Atas (SMA) di daerah Jawa Tengah.

Media pembelajaran Bahasa Jawa sebenarnya sudah tersedia yaitu menggunakan pustaka Pepak Basa Jawa. Walaupun hanya sebagian kecil tentang pengetahuan Bahasa Jawa, namun Pepak Basa Jawa ini sudah mencakup keseluruhan hal yang penting untuk dipelajari. Pepak Basa Jawa merupakan sebuah buku yang berisi kumpulan kata, kosakata, kalimat, sastra, benda, tingkah laku, makhluk hidup, tokoh pewayangan, dan lain sebagainya dalam Bahasa Jawa. Kegunaan Pepak Basa Jawa itu sendiri adalah sebagai sumber pustaka yang dapat dengan mudah dipelajari karena disajikan secara praktis.

Teknologi saat ini berkembang semakin cepat dan banyak memberikan kemudahan bagi para penggunanya, seperti kemudahan dalam memperoleh informasi, kemudahan komunikasi, kemudahan mengolah data dan kemudahan di dalam bidang yang lainnya. Dengan perkembangan teknologi yang sangat cepat ini, manusia beralih meninggalkan cara-cara lama untuk mengikuti teknologi yang serba mudah. Salah satu teknologi yang serba mudah adalah dengan adanya gadget.

Pada zaman serba teknologi seperti sekarang, gadget tidak lagi menjadi barang asing bagi siapapun. Bahkan anak-anak kecil pun sudah banyak yang bermain dengan gadget. Fungsi gadget sendiri diantaranya adalah untuk telepon, mengirim Short Message Service (SMS), mengirim Multimedia Message Service (MMS), bermain game, pemutar musik \& video, browsing internet, dan masih banyak lagi. Namun, alangkah baiknya apabila gadget dijadikan sebagai media pembelajaran karena akan menjadi lebih bermanfaat.

Berdasarkan latar belakang di atas, muncul ide untuk merancang dan membuat sebuah aplikasi Pepak Basa Jawa yang dirancang untuk perangkat iOS yaitu iPad dengan menggunakan perangkat lunak MobiOne Studio. Penggunaan perangkat lunak MobiOne Studio karena penampilannya menarik, user friendly, dan mudah digunakan. Perancangan dan pembuatan aplikasi Pepak Basa Jawa ini diharapkan mampu memberikan alternatif agar dapat memberikan kemudahan bagi masyarakat Indonesia untuk mempelajari dan melestarikan budaya Indonesia yaitu Bahasa Jawa.

\subsection{Tujuan}

Tugas akhir ini mempunyai tujuan, yaitu:

1. Merancang dan membuat aplikasi berbasis mobile sebagai media pembelajaran untuk mempelajari dan melestarikan Bahasa Jawa.

2. Memberikan alternatif sarana belajar yang praktis agar dapat memberikan kemudahan untuk mempelajari Bahasa Jawa bagi pengguna. 


\subsection{Batasan Masalah}

Dalam pembuatan tugas akhir ini pembahasan masalah memiliki batasan pada permasalahan berikut:

a. Aplikasi ini hanya dapat dijalankan pada perangkat iOS yaitu iPad.

b. Aplikasi ini dijalankan pada sistem operasi iOS versi $7 \mathrm{ke}$ atas.

c. Rancangan dan pembuatan aplikasi Pepak Basa Jawa ini berisi 4 materi utama Bahasa Jawa yaitu kawruh basa (tetuwuhan, kewan, manungsa, kamus), kasusastran (tembang macapat, tembang dolanan, gamelan), pewayangan (punakawan, pandawa, dewadewi, ramayana) dan hanacaraka (aksara jawa, pasangan jawa, sandhangan, angka jawa) serta dilengkapi dengan latihan soal.

d. Aplikasi ini dibuat menggunakan perangkat lunak MobiOne Studio.

\section{LANDASAN TEORI}

\subsection{Budaya Jawa}

Jawa (Java), atau sebutan lain Djawa Dwipa atau Jawi adalah pulau yang terletak di tepi selatan kepulauan Indonesia. Orang Jawa (Javanese) adalah orang yang memakai bahasa Jawa sebagai bahasa ibu dan merupakan penduduk asli bagian tengah dan timur Pulau Jawa ${ }^{[7]}$.

Suku Jawa merupakan suku bangsa terbesar di Indonesia yang berasal dari Jawa Tengah, Jawa Timur, dan Daerah Istimewa Yogyakarta. Setidaknya $45 \%$ penduduk Indonesia merupakan etnis Jawa ${ }^{[6]}$.

\subsection{Aplikasi Mobile}

Aplikasi mobile adalah perangkat lunak yang berjalan pada perangkat mobile seperti gadget atau tablet PC. Aplikasi mobile juga dikenal sebagai aplikasi yang dapat diunduh dan memiliki fungsi tertentu sehingga menambah fungsionalitas dari perangkat mobile itu sendiri ${ }^{[8]}$.

\section{3 iOS}

iOS adalah sistem operasi yang berjalan pada iPhone, iPod touch, dan perangkat iPad. Sistem operasi mengelola perangkat keras dan menyediakan teknologi yang dibutuhkan untuk mengimplementasikan aplikasi asli. Sistem operasi merupakan induk dari berbagai aplikasi sistem, seperti Telepon, Mail, dan Safari, yang menyediakan layanan sistem standar untuk pengguna [5].

\subsection{1 iPad}

iPad merupakan salah satu sebuah produk komputer tablet buatan Apple Incorporation (AI). iPad memiliki bentuk tampilan yang hampir serupa dengan iPod Touch dan iPhone, hanya saja ukurannya lebih besar dibandingkan kedua produk tersebut dan memiliki fungsi-fungsi tambahan seperti yang ada pada sistem operasi Mac OS $\mathrm{X}^{[2]}$.

\subsection{MobiOne Studio}

MobiOne Studio merupakan development tools dari Genuitec. MobiOne Studio dengan keunggulan utamanya memang layak untuk dipertimbangkan oleh
Komunitas Developer Apple. Berikut merupakan fiturfitur unggulan MobiOne Studio ${ }^{[9]}$ :
a. Cross Platform
b. WYSIWYG (What You See Is What You Get)
c. App dan WebApp Generator
d. Operating System Windows
e. iOS dan Android Emulator
f. Inspeksi dan Debug
g. Build Native Application di Cloud
h. Over the Air Application Installation
i. Publish Mobile Webapps

\subsection{MyEclipse 2015 CI}

MyEclipse 2015 CI adalah salah satu produk terbaru dari Genuitec yang merupakan alat pengembang untuk membuat aplikasi mobile berbasis Android dan iOS dari project Mobione Studio ${ }^{[4]}$.

\subsection{GapDebug}

GapDebug juga adalah salah satu produk dari Genuitec yang berfungsi sebagai alat mobile debugging. GapDebug dapat berjalan pada platform Mac atau Windows. GapDebug mengijinkan untuk debugging aplikasi perangkat bergerak yang hybrid, seperti PhoneGap dan Cordova, pada perangkat modern seperti Android dan iOS. Untuk melakukan lokal debugging, GapDebug selalu dilakukan secara gratis $^{[3]}$.

\subsection{CorelDraw X4}

CorelDraw adalah sebuah software desain grafis yang sangat terkenal dan termasuk sebagai salah satu aplikasi pengolah gambar berbasis vektor. Berbagai fasilitas untuk keperluan desain tersedia dalam program ini, sehingga memudahkan para pengguna untuk memanfaatkannya. CorelDraw sering digunakan untuk membuat gambar kartun, logo, ilustrasi. Contoh penggunaan CorelDraw antara lain untuk membuat brosur, surat undangan, dan sebagainya [12].

\subsection{Multimedia}

Multimedia adalah sebuah kombinasi yang saling berkaitan dari teks, foto dan gambar, suara, animasi, dan video yang dimanipulasi secara digital ${ }^{[11]}$. Multimedia memiliki beberapa objek seperti teks, suara, video, gambar, dan animasi.

\subsubsection{Metode MDLC (Multimedia Development Life Cycle) \\ MDLC (Multimedia Development Life Cycle)} merupakan pengembangan multimedia yang terdiri dari enam tahap, yaitu konsep (concept), desain (design), pengumpulan materi (material collecting), pembuatan (assembly), pengujian (testing), dan distribusi (distribution). Keenam tahap ini tidak harus berurutan dalam prakteknya, tahap-tahap tersebut dapat saling bertukar posisi. Meskipun begitu, tahap konsep memang harus menjadi hal yang pertama kali dikerjakan ${ }^{[1]}$.

Tahapan pengembangan multimedia ditunjukkan oleh Gambar 1. 


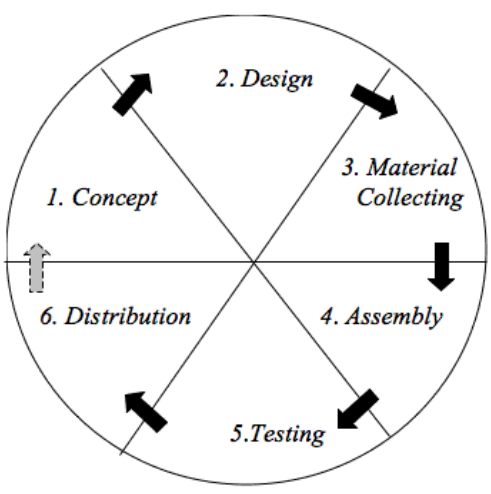

Gambar 1. Tahapan pengembangan multimedia ${ }^{[10]}$

III. PERANCANGAN SISTEM

3.1 Tahap Pengembangan Multimedia

\section{A. Konsep}

Aplikasi ini dibuat sebagai suatu media pembelajaran yang interaktif bagi masyarakat Indonesia, khususnya pelajar mulai dari Sekolah Dasar (SD), Sekolah Menengah Pertama (SMP) hingga Sekolah Menengah Atas (SMA). Aplikasi media pembelajaran ini dibuat untuk memberikan kemudahan bagi pengguna serta lebih praktis dan lebih tertarik dalam mempelajarinya. Aplikasi yang dibuat adalah Pepak Basa Jawa yang merupakan dasar-dasar dari Bahasa Jawa. Pepak Basa Jawa ini terdiri dari empat pokok materi yaitu kawruh basa, kasusastran, pewayangan, dan hanacaraka serta dilengkapi dengan latihan soal.

\section{B. Desain}

1. Struktur Navigasi Hirarki

Struktur navigasi memberikan gambaran link dari halaman satu ke halaman lainnya. Struktur navigasi hirarki aplikasi ditunjukkan oleh Gambar 2.

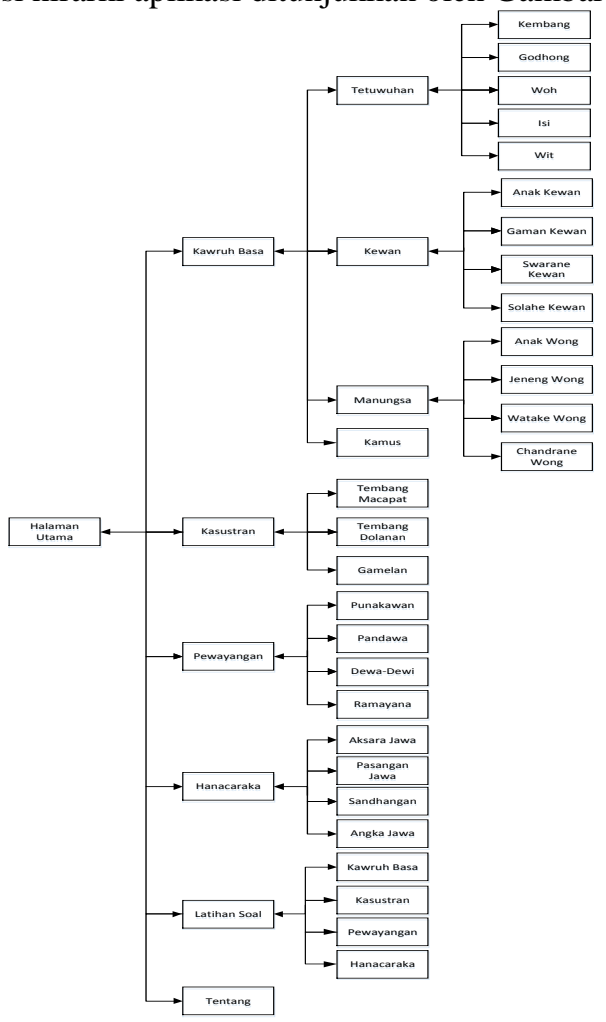

Gambar 2. Struktur Navigasi Hirarki

\section{Diagram Alir}

Diagram alir digunakan untuk menjelaskan tentang alur program yang dibuat. Diagram alir proses memilih kembang ditunjukkan oleh Gambar 3.

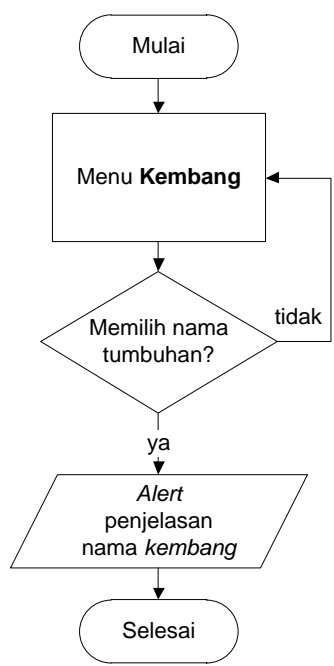

Gambar 3. Diagram alir proses memilih kembang

Diagram alir proses memilih anak kewan ditunjukkan oleh Gambar 4.

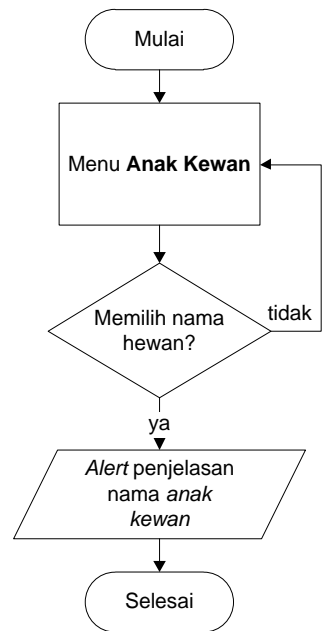

Gambar 4. Diagram alir proses memilih anak kewan

Diagram alir proses memilih anak wong ditunjukkan oleh Gambar 5.

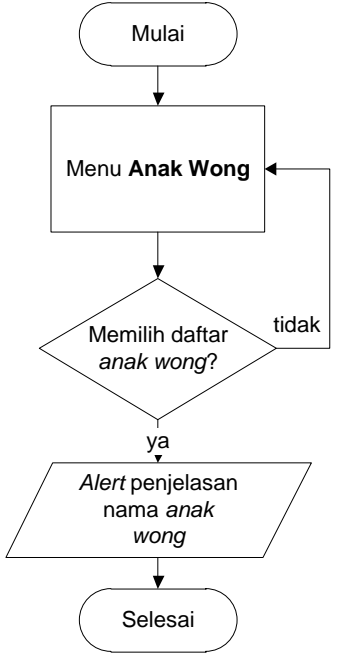

Gambar 5. Diagram alir proses memilih anak wong 
Diagram alir proses memilih kamus ditunjukkan oleh Gambar 6.

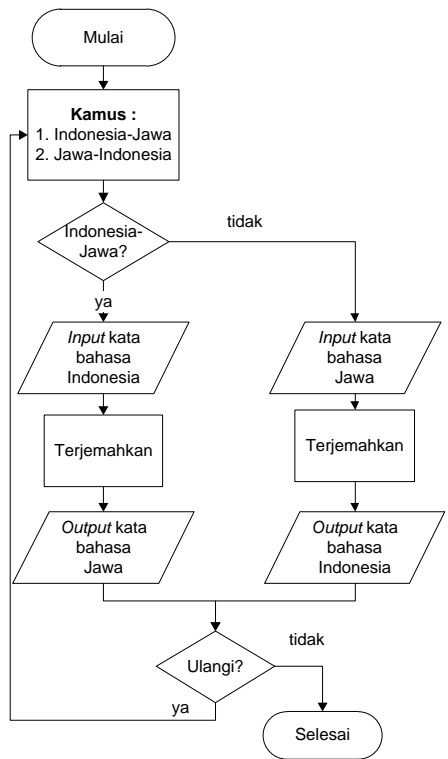

Gambar 6. Diagram alir proses memilih kamus

Diagram alir proses memilih tembang dolanan ditunjukkan oleh Gambar 7.

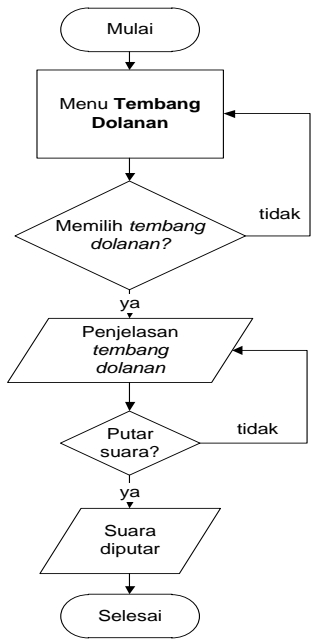

Gambar 7. Diagram alir proses memilih tembang dolanan

Diagram alir proses memilih punakawan ditunjukkan oleh Gambar 8.

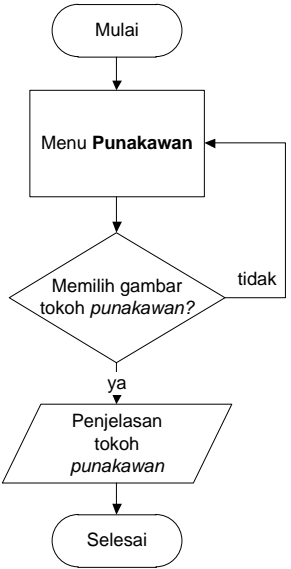

Gambar 8. Diagram alir proses memilih punakawan
Diagram alir proses memilih aksara jawa ditunjukkan oleh Gambar 9.

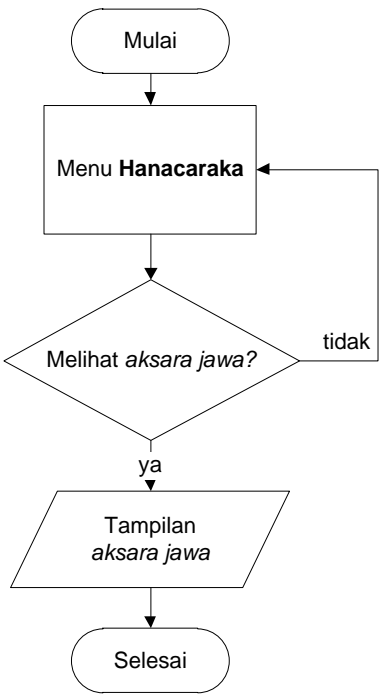

Gambar 9. Diagram alir proses memilih aksara jawa

Diagram alir latihan soal kasusastran ditunjukkan oleh Gambar 10.

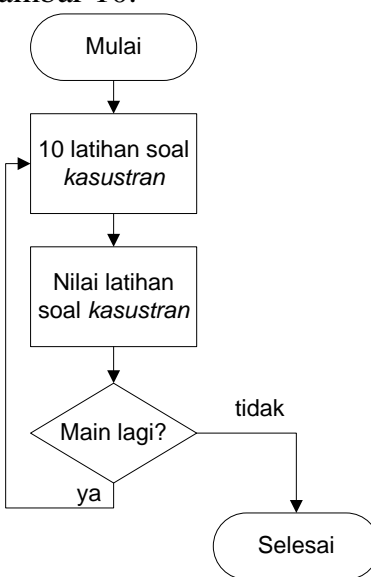

Gambar 10. Diagram alir latihan soal kasusastran

\section{Use Case Diagram}

Use case merupakan gambaran skenario dari interaksi antara user dengan sistem. Use case menggambarkan hubungan antara aktor dan kegiatan yang dapat dilakukannya terhadap aplikasi. Use case diagram aplikasi pepak basa jawa ditunjukkan oleh Gambar 11

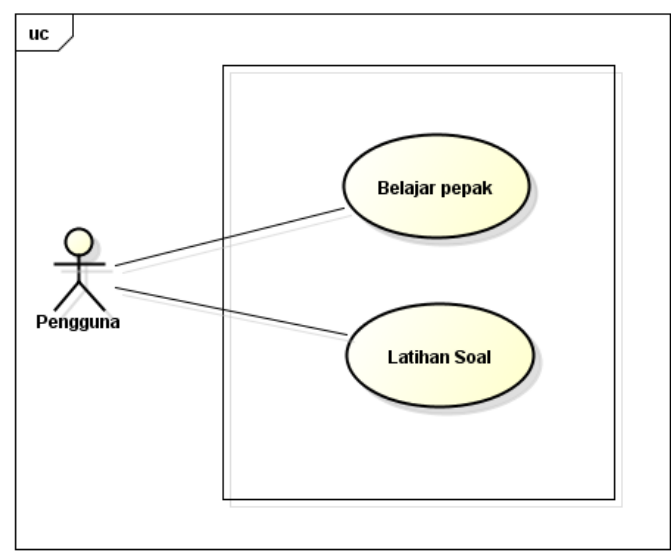

Gambar 11. Use case diagram pepak basa jawa 


\section{Sequence Diagram}

Sequence diagram menggambarkan interaksi antar objek di dalam dan di sekitar sistem (termasuk pengguna, display, dan sebagainya) berupa message yang digambarkan terhadap waktu. Sequence diagram belajar pepak ditunjukkan oleh Gambar 12.

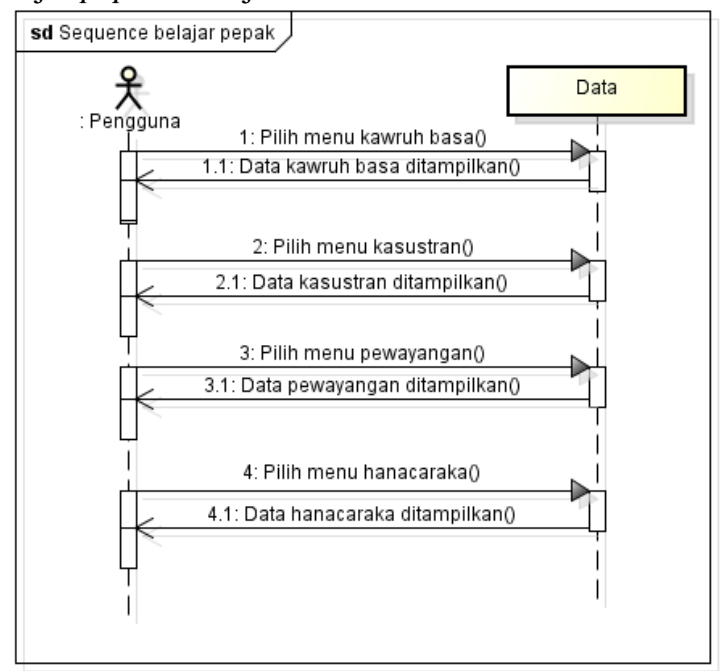

Gambar 12. Sequence diagram belajar pepak

Sequence diagram latihan soal kawruh basa ditunjukkan oleh Gambar 13.

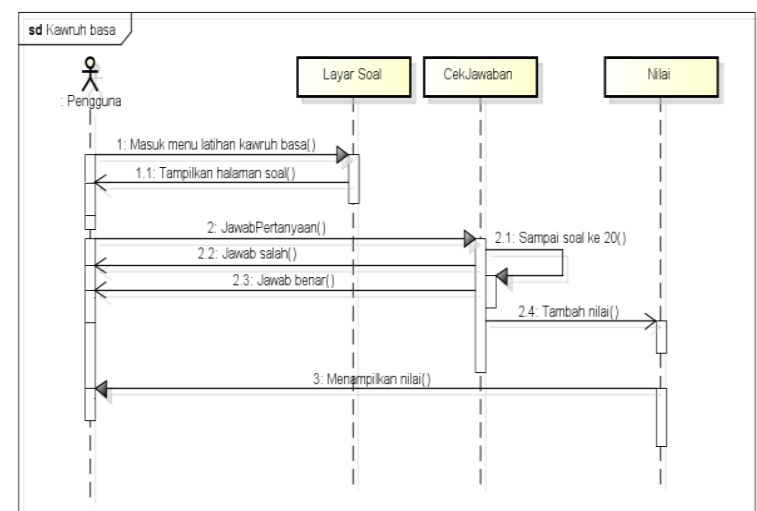

Gambar 13. Sequence diagram latihan soal kawruh basa

Sequence diagram latihan soal kasusastran ditunjukkan oleh Gambar 14.

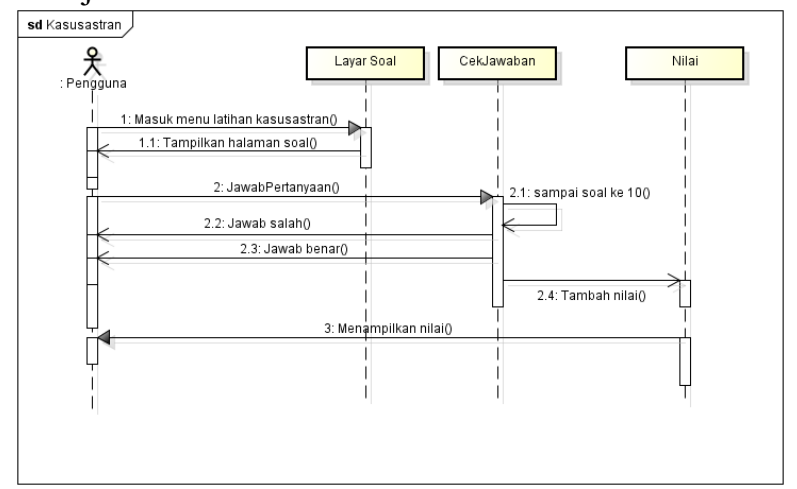

Gambar 14. Sequence diagram latihan soal kasusastran

\section{Desain Content}

Desain content merupakan desain yang berisi isi materi dari masing-masing menu atau sub menu.
Desain content menu tembang macapat ditunjukkan oleh Tabel ..

Tabel 1. Desain content menu tembang macapat

\begin{tabular}{|c|c|c|c|}
\hline \multicolumn{4}{|c|}{ Tembang Macapat } \\
\hline Mijil & Sinom & Gambuh & Megatruh \\
\hline Maskumambang & Dhandhanggula & Durma & Pocung \\
\hline Kinanthi & Asmarandana & Pangkur & \multicolumn{1}{|c}{} \\
\cline { 1 - 2 } & &
\end{tabular}

6. Desain Antarmuka

Desain antarmuka digunakan agar pengguna mengetahui gambaran tampilan sesungguhnya sebelum aplikasi selesai dibuat.

\section{Pengumpulan Materi}

Dalam tahap ini dilakukan pengumpulan materi Bahasa Jawa seperti yang terdapat dalam buku Pinter Basa Jawi Pepak dan disempurnakan dengan menambahkan materi dari hasil cari internet. Pengumpulan gambar pada tokoh wayang dan gamelan didapat dari hasil cari internet. Untuk cerita tokoh pewayangan diambil dari buku Atlas Tokoh Wayang. Bahan audio dan video untuk memperjelas contoh tembang macapat dan tembang dolanan didapat dari internet. Untuk gambar background dibuat dengan menggunakan perangkat lunak CorelDraw X4.

\section{Pembuatan}

Alat dan bahan yang digunakan dalam pembuatan aplikasi Pepak Bahasa Jawa ini adalah sebagai berikut.

a. Perangkat keras

- Laptop Toshiba Satellite L200

- $\quad$ Ipad 2

b. Perangkat lunak

- Microsoft Windows 7

- MobiOne Studio

- MyEclipse 2015 CI

- GapDebug

- CorelDraw X4

- Adobe Photoshop

\section{E. Pengujian}

Pada tahap pengujian dilakukan pengujian pada aplikasi yang dibuat dengan metode Black-Box Test yaitu dengan melihat fungsi-fungsi per menu sudah sesuai atau tidak.

\section{F. Distribusi}

Setelah pengujian setiap fungsi berhasil, maka aplikasi disimpan lalu di build untuk mendapat file ekstensi .ipa. Setelah mendapat file .ipa kemudian di distribusikan dan dilakukan proses instalasi pada perangkat iPad yang sesungguhnya.

\section{PEMBUATAN DAN PENGUJIAN \\ 4.1 Hasil Pembuatan Aplikasi Pepak Bahasa Jawa}

1. Tampilan halaman utama

Halaman utama merupakan halaman awal ketika aplikasi dijalankan. Halaman utama terdiri dari 6 menu 
utama. Tampilan halaman utama ditunjukkan oleh Gambar 15.

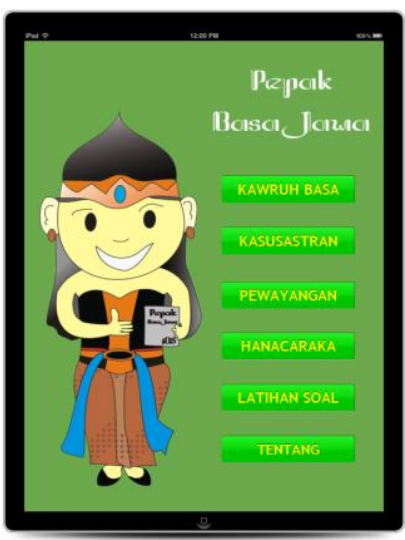

Gambar 15. Tampilan halaman utama

\section{Tampilan menu kawruh basa}

Menu kawruh basa adalah menu yang berisi sekumpulan kata-kata dalam Bahasa Jawa. Kawruh basa ini dikelompokkan menjadi 4 yaitu tetuwuhan (tumbuhan), kewan (hewan), manungsa (manusia) dan kamus untuk melakukan terjemahan. Tampilan menu kawruh basa ditunjukkan oleh Gambar 16 .

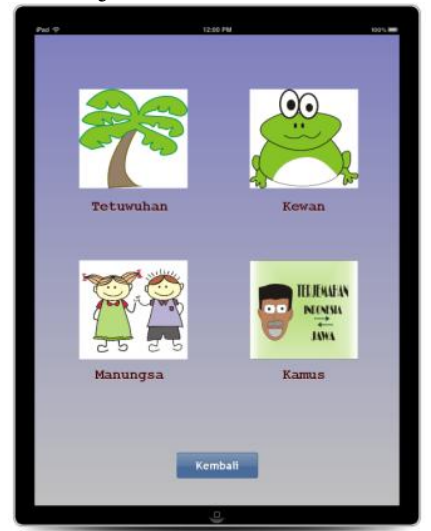

Gambar 16. Tampilan menu kawruh basa

- Tampilan sub menu tetuwuhan

Pada sub menu tetuwuhan akan ditampilkan menu bagian tumbuhan yang lebih spesifik untuk dibahas. Terdapat 5 sub menu yaitu kembang (bunga), godhong (daun), woh (buah), isi, wit (pohon). Tampilan sub menu tetuwuhan ditunjukkan oleh Gambar 17.

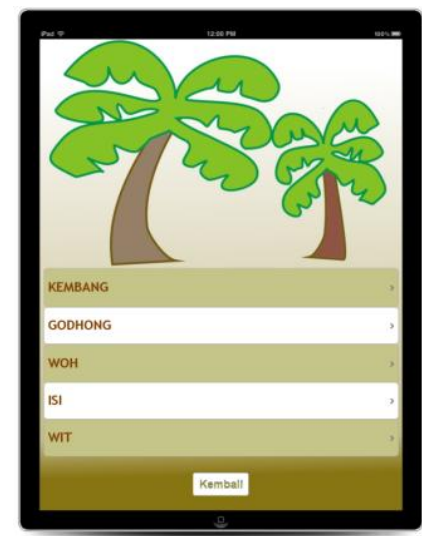

Gambar 17. Tampilan sub menu tetuwuhan
Tampilan daftar nama-nama tumbuhan ditunjukkan oleh Gambar 18.

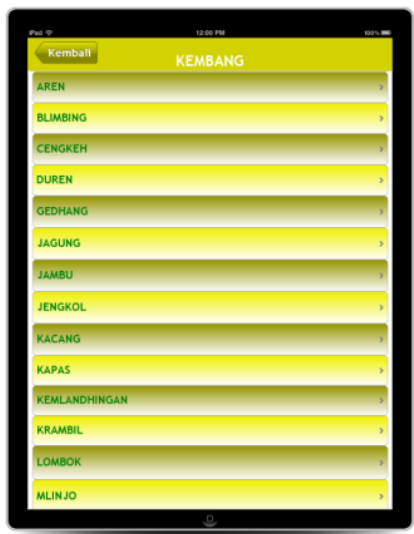

Gambar 18. Tampilan daftar nama-nama tumbuhan

Alert penjelasan tetuwuhan ditunjukkan oleh Gambar 19.

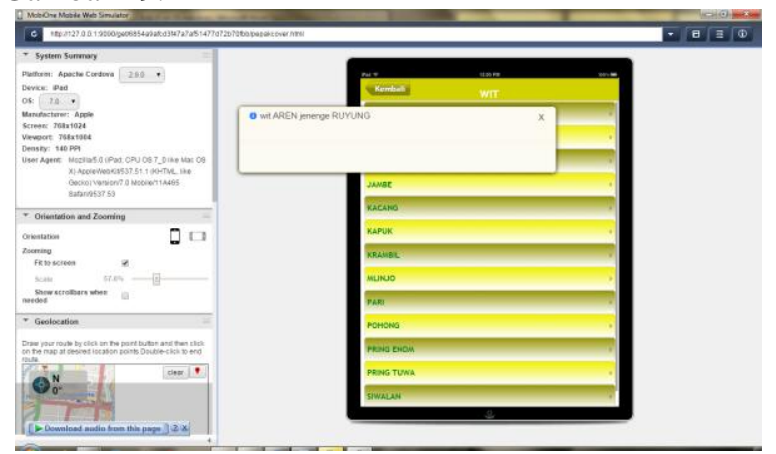

Gambar 19. Alert penjelasan tetuwuhan

- Tampilan sub menu kamus

Sub menu kamus merupakan sub menu yang berfungsi untuk menerjemahkan kata atau kalimat dari Bahasa Indonesia ke Bahasa Jawa atau sebaliknya. Tampilan menu kamus ditunjukkan oleh Gambar 20.

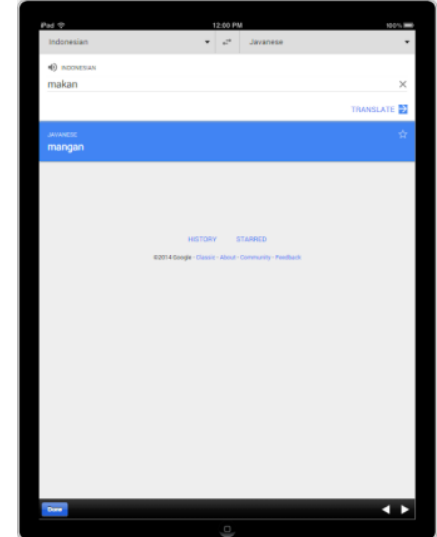

Gambar 20. Tampilan sub menu kamus

3. Tampilan menu kasusastran

Menu kasusastran merupakan menu yang berupa sastra dalam Bahasa Jawa. Menu kasustran ini terdiri dari 3 sub menu, yaitu sub menu tembang macapat, tembang dolanan, dan sub menu gamelan. Tampilan menu kasusastran ditunjukkan oleh Gambar 21. 


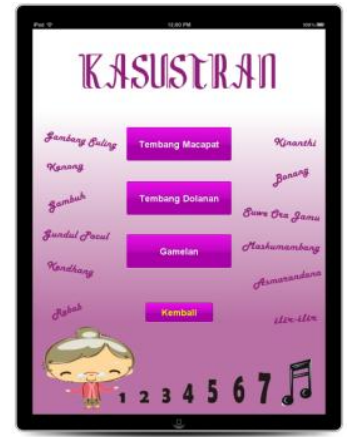

Gambar 21. Tampilan menu kasusastran

- Tampilan sub menu tembang macapat

Sub menu tembang macapat merupakan menu yang berisi 11 tembang macapat. Ketika daftar tembang macapat dipilih salah satu, maka selanjutnya akan muncul halaman yang terdiri dari sifat tembang, lirik tembang, dan link video. Tampilan sub menu tembang macapat ditunjukkan oleh Gambar 22 ..

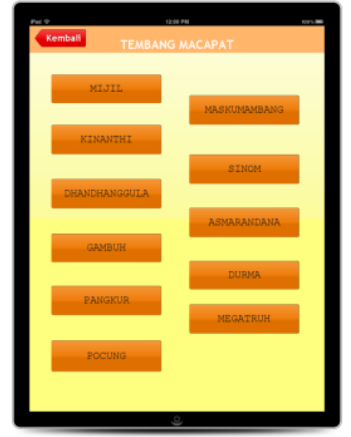

Gambar 22. Tampilan sub menu tembang macapat

Tampilan pilihan tembang macapat ditunjukkan oleh Gambar 23.

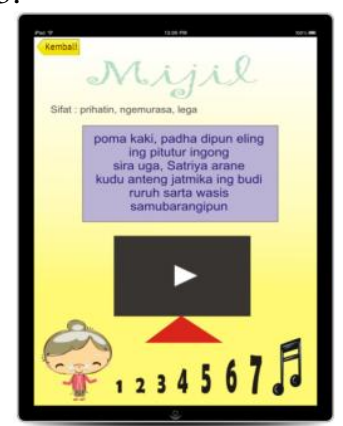

Gambar 23. Tampilan pilihan tembang macapat

Tampilan link video ditunjukkan oleh Gambar

24.

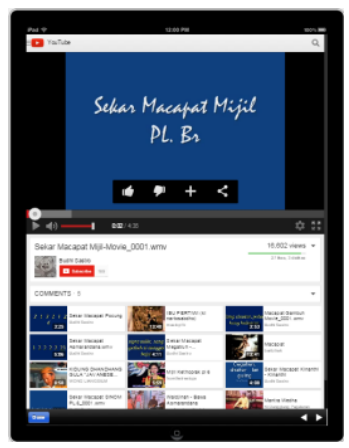

Gambar 24. Tampilan link video pilihan tembang macapat
- Tampilan sub menu gamelan

Sub menu gamelan merupakan menu yang berisi tentang macam-macam nama perangkat gamelan. Tampilan sub menu gamelan ditunjukkan oleh Gambar 25 .

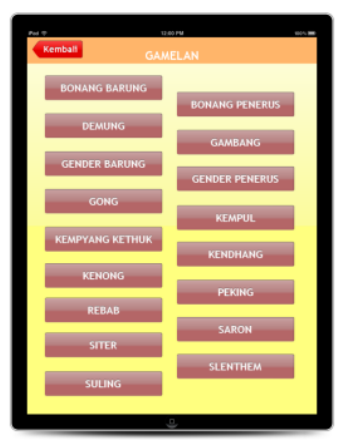

Gambar 25. Tampilan sub menu gamelan

Tampilan pilihan perangkat gamelan ditunjukkan oleh Gambar 26.

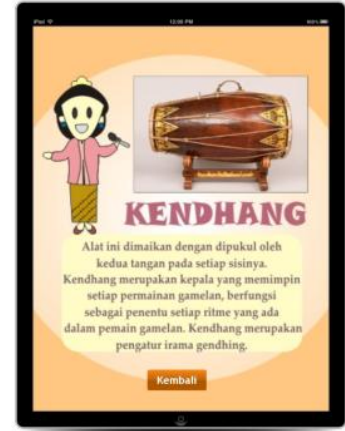

Gambar 26. Tampilan pilihan perangkat gamelan

4. Tampilan menu pewayangan

Menu pewayangan merupakan menu yang berisi tokoh-tokoh pewayangan. Menu pewayangan terdiri dari 4 sub menu, yaitu sub menu punakawan, pandawa, dewa-dewi, dan ramayana. Tampilan menu pewayangan ditunjukkan oleh Gambar 27.

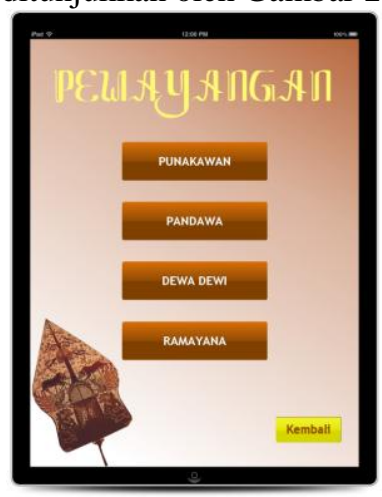

Gambar 27. Tampilan menu pewayangan

- Tampilan sub menu punakawan

Sub menu punakawan merupakan menu yang terdiri dari nama tokoh punakawan dan gambar tokoh punakawan. Tampilan sub menu punakawan ditunjukkan oleh Gambar 28. 


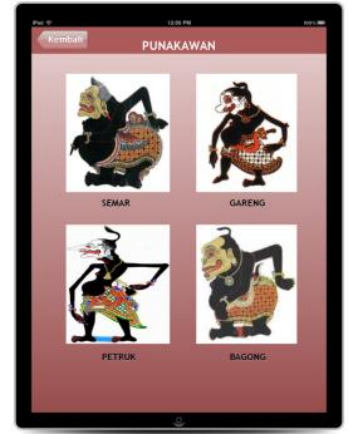

Gambar 28. Tampilan sub menu punakawan Gambar 29 .

Tampilan pilihan punakawan ditunjukkan oleh

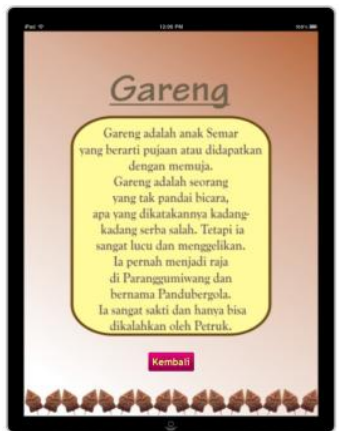

Gambar 29. Tampilan pilihan punakawan

\section{Tampilan menu hanacaraka}

Menu hanacarak $a$ merupakan menu yang berisi tentang huruf Jawa. Menu hanacaraka terdiri dari 4 sub menu, yaitu aksara jawa, pasangan jawa, sandhangan, dan angka jawa. Tampilan menu hanacaraka ditunjukkan oleh Gambar 30.

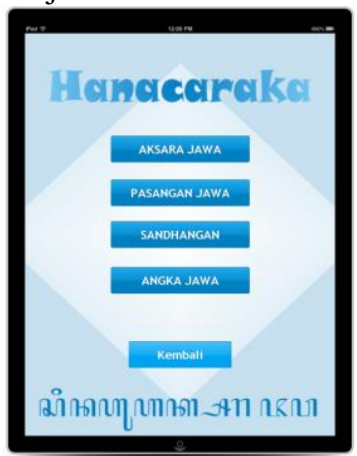

Gambar 30. Tampilan menu hanacaraka

Tampilan sub menu aksara jawa ditunjukkan oleh Gambar 31.

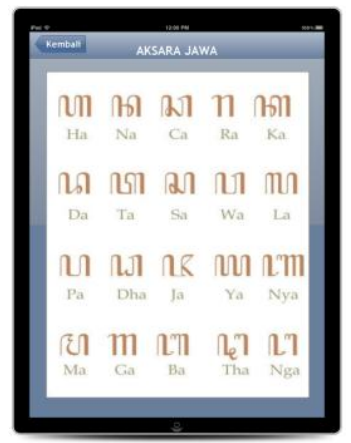

Gambar 31. Tampilan sub menu aksara jawa
6. Tampilan menu latihan soal

Menu latihan soal adalah menu yang berisi kumpulan pertanyaan berdasarkan sub menu yang telah dipelajari sebelumnya. Latihan soal ini terdiri dari kawruh basa, kasustran, pewayangan, dan hanacaraka. Tampilan latihan soal hanacaraka ditunjukkan oleh Gambar 32.

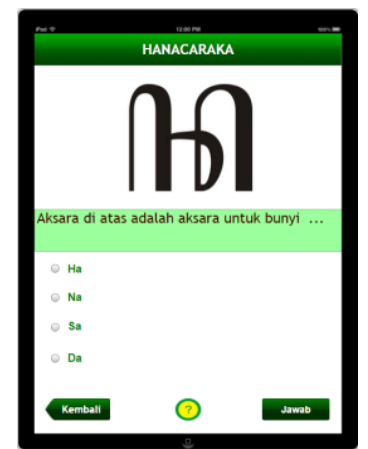

Gambar 32. Tampilan latihan soal hanacaraka

Ketika jawaban yang dipilih benar maka akan muncul alert seperti yang ditunjukkan oleh Gambar 33.

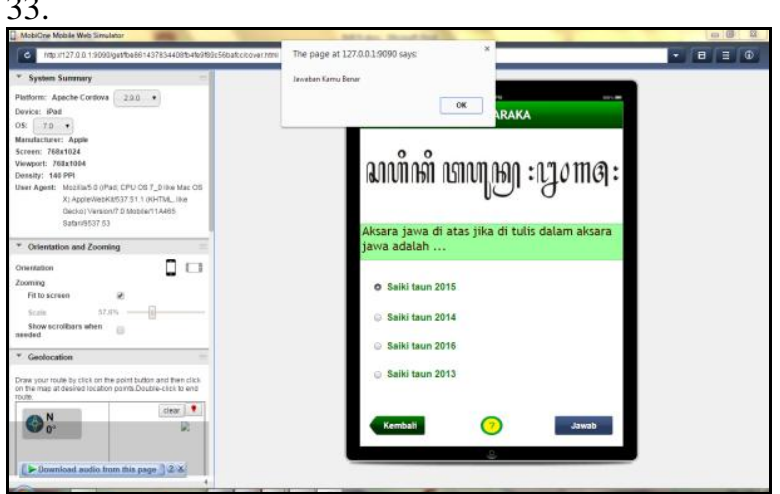

Gambar 33. Tampilan alert jawaban benar latihan soal hanacaraka

Setelah 10 pertanyaan selesai, maka selanjutnya akan muncul tampilan nilai seperti yang ditunjukkan oleh Gambar 34.

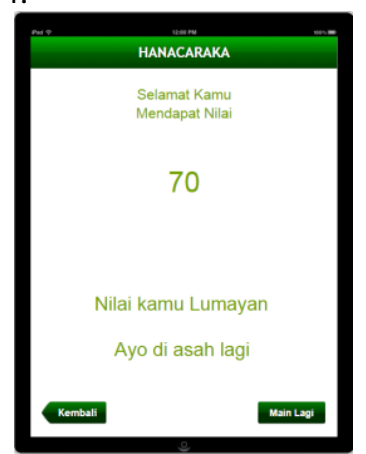

Gambar 34. Tampilan nilai latihan soal hanacaraka

\subsection{Pengujian Aplikasi}

Pengujian aplikasi Pepak Bahasa Jawa ini dilakukan dengan menggunakan metode black-box. Pengujian black-box merupakan pengujian yang dilakukan untuk menunjukkan fungsi program yang dibuat berdasarkan cara operasi dan kegunaannya apakah keluaran yang dihasilkan sesuai dengan yang diharapkan. Pengujian ini dilakukan untuk mengetahui 
apakah masih terjadi kesalahan pada program atau program sudah berhasil diselesaikan dengan benar.

Tabel 2. Tabel pengujian aplikasi secara keseluruhan

\begin{tabular}{|c|c|c|c|}
\hline $\begin{array}{c}\text { Nama } \\
\text { Pengujian }\end{array}$ & $\begin{array}{c}\text { Bentuk } \\
\text { Pengujian }\end{array}$ & $\begin{array}{c}\text { Hasil yang } \\
\text { Diharapkan }\end{array}$ & $\begin{array}{c}\text { Hasil } \\
\text { Pengujian }\end{array}$ \\
\hline $\begin{array}{l}\text { Pengujian } \\
\text { menu } \\
\text { Kawruh } \\
\text { Basa }\end{array}$ & $\begin{array}{l}\text { Menyentuh } \\
\text { menu } \\
\text { Kawruh } \\
\text { Basa }\end{array}$ & $\begin{array}{l}\text { Tampil } \\
\text { halaman sub } \\
\text { menu kawruh } \\
\text { basa }\end{array}$ & Berhasil \\
\hline $\begin{array}{l}\text { Pengujian } \\
\text { menu } \\
\text { Kasusastran }\end{array}$ & $\begin{array}{l}\text { Menyentuh } \\
\text { menu } \\
\text { Kasusastran }\end{array}$ & $\begin{array}{l}\text { Tampil } \\
\text { halaman sub } \\
\text { menu } \\
\text { kasusastran }\end{array}$ & Berhasil \\
\hline $\begin{array}{l}\text { Pengujian } \\
\text { menu } \\
\text { Pewayangan }\end{array}$ & $\begin{array}{l}\text { Menyentuh } \\
\text { menu } \\
\text { Pewayangan }\end{array}$ & $\begin{array}{l}\text { Tampil } \\
\text { halaman sub } \\
\text { menu } \\
\text { pewayangan }\end{array}$ & Berhasil \\
\hline $\begin{array}{l}\text { Pengujian } \\
\text { menu } \\
\text { Hanacaraka }\end{array}$ & $\begin{array}{l}\text { Menyentuh } \\
\text { menu } \\
\text { Hanacaraka }\end{array}$ & $\begin{array}{l}\text { Tampil } \\
\text { halaman sub } \\
\text { menu } \\
\text { hanacaraka }\end{array}$ & Berhasil \\
\hline $\begin{array}{l}\text { Pengujian } \\
\text { menu } \\
\text { Latihan } \\
\text { Soal }\end{array}$ & $\begin{array}{l}\text { Menyentuh } \\
\text { menu } \\
\text { Latihan } \\
\text { Soal }\end{array}$ & $\begin{array}{l}\text { Tampil } \\
\text { halaman } \\
\text { latihan soal }\end{array}$ & Berhasil \\
\hline $\begin{array}{l}\text { Pengujian } \\
\text { menu } \\
\text { Tentang }\end{array}$ & $\begin{array}{l}\text { Menyentuh } \\
\text { menu } \\
\text { Tentang }\end{array}$ & $\begin{array}{l}\text { Tampil } \\
\text { halaman } \\
\text { tentang }\end{array}$ & Berhasil \\
\hline
\end{tabular}

\section{PENUTUP}

\subsection{Kesimpulan}

Kesimpulan dalam pembuatan Tugas Akhir aplikasi pepak bahasa Jawa diantaranya adalah sebagai berikut

1. Aplikasi Pepak Basa Jawa dapat dibuat dengan baik dengan menggunakan perangkat lunak MobiOne Studio yang terdiri dari 4 pokok materi yaitu kawruh basa, kasusastran, pewayangan, dan hancaraka sehingga dapat digunakan sebagai alternatif sarana belajar yang praktis untuk mempelajari Bahasa Jawa.

2. Aplikasi Pepak Basa Jawa dapat didistribusikan dan berjalan dengan baik pada perangkat bergerak dengan sistem operasi iOS yaitu iPad versi 7 ke atas.

3. Berdasarkan hasil pengujian aplikasi Pepak Basa Jawa menggunakan Black Box Test, seluruh fungsi menu yang ada dalam aplikasi telah berhasil sesuai dengan fungsinya.

\subsection{Saran}

Saran yang dapat diberikan penulis untuk pengembangan aplikasi selanjutnya adalah sebagai berikut.

1. Perlu dilakukan penambahan materi seperti unggah-ungguh basa (ngoko, krama madya, krama inggil) dan cara pengucapan kata serta referensi untuk aplikasi agar penyajiannya semakin lengkap.

2. Perlu dilakukan penelitian lanjutan untuk mengembangkan aplikasi pada perangkat selain iPad.

3. Aplikasi dapat dikembangkan dengan menggunakan database sehingga aplikasi dapat dijalankan tanpa terhubung dengan internet.

\section{DAFTAR PUSTAKA}

[1] Binanto, Iwan, Multimedia Digital - Dasar Teori dan Pengembangannya, Andi, Yogyakarta, 2010.

[2] Gayatri, Womens Guide, Gagas Media, Jakarta, 2011.

[3] Genuitec, GapDebug Features, https://www.genuitec.com/products/gapdebug/fea tures/, 22 Mei 2015.

[4] Genuitec, MyEclipse Features, https://www.genuitec.com/products/myeclipse/fea tures/, 22 Mei 2015.

[5] Goldstein, Neal. Paris Buttfield-Addison. Jon Manning, iPhone \& iPad Game Development For Dummies, Wiley Publishing,Inc., Indianapolis, 2011.

[6] Indonesia's Population: Ethnicity and Religion in a Changing Political Landscape. Institute of Southeast Asian Studies. 2003.

[7] Magnis, Dr Franz dan Suseno S.J., Etika Jawa; sebuah analisa Falsafi Tentang

Kebijaksanaan Hidup Jawa, PT Gramedia Pustaka Utama, Jakarta, 2003.

[8] Mobile Marketing Association, Mobile Application.

http://mmaglobal.com/mobileapplications.pdf, 12 Juli 2014.

[9] Renga, Membuat Aplikasi Mobile dengan MobiOne Studio, http://www.hakaonline.net/2012/06/09/membuataplikasi-mobile-dengan- mobione-studio/, 31 Mei 2014

[10] Sutopo, Ariesto Hadi, Multimedia Interaktif dengan Flash, Graha Ilmu. Yogyakarta, 2003.

[11] Vaughan, Tay, Multimedia: Making It Work Eighth, McGraw-Hill, New York, 2011.

[12] Pranowo, G., Mastering CorelDRAW X4, Andi, Yogyakarta, 2010. 